\title{
Medicolegal
}

\section{Dr Gee cleared of serious professional misconduct}

\author{
CLARE DYER
}

On 23 March the professional conduct committee of the General Medical Council cleared Dr Sidney Gee, a general practitioner in private practice in Rochester, Kent, and Harley Street, of serious professional misconduct. The hearing had been delayed for four years, first to allow Dr Gee's celebrated libel action against the BBC to go ahead and later while he took the first ever judicial challenge to the formulation of the council's charges all the way to the House of Lords. His claim that the charges were prejudicial to him because they were duplicitous-with complaints relating to different patients rolled up into one instead of being split into separate charges - and that allegations about four patients that had not been through the preliminary sifting procedure could not go ahead were rejected by the House of Lords last May.

\section{The charges}

Dr Gee was charged with abusing his position as a doctor by supplying drugs, including dexamphetamine sulphate and thyroid extract, without $(a)$ adequately examining patients or seeking adequate information about their medical history, $(b)$ consulting their general practitioners first or notifying them afterwards, $(c)$ making adequate inquiries about the effect of the treatment on patients' health, and $(d)$ offering appropriate advice when patients reported harmful effects.

The professional conduct committee found the facts under $(a),(c)$, and $(d)$ not proved. On count $(b)$, although it found the facts proved, it decided that the facts did not amount to serious professional misconduct.

The charges originally referred to four patients, including Mrs Elizabeth Day, the patient featured on the That's Life programme that led to the libel action. (The case was settled when the BBC and the two doctors sued by Dr Gee agreed to pay $£ 100000$ damages and costs.) Charges relating to seven patients eventually went ahead. After an unsuccessful application by Dr Gee to have the hearing held in camera, Vivian Robinson QC, counsel for the General Medical Council, stressed in opening the case that it was no part of the council's case to impugn Dr Gee's drug treatment. This case, he said, concerned things left undone, not things done.

Mrs Day told the committee that the treatment caused her tremors, nausea, and deterioration. She said she aged visibly, her hair started falling out, and her nails kept breaking. She also complained of a dry mouth, blurred eyesight, palpitations, and a pulse rate of 147. But despite her complaints she was not given a proper physical examination, she said. Dr Gee took her blood pressure only twice during eight months of treatment.

Dr Roger Blackwood, consultant physician and cardiologist at St Edward's Hospital, Windsor, who treated Mrs Day told the hearing he was "astonished to find somebody being treated for obesity in this way." A letter from Dr Blackwood asking Dr Gee for information about the drugs prescribed was quoted on That's Life, and he and Dr Clemency Mitchell, Mrs Day's general practitioner, were also sued for libel.

\section{London NW1}

CLARE DYER, BA, BLS, legal correspondent
Another witness, Mrs Beverly Vivash, the mother of an 11 year old boy treated by Dr Gee told the hearing that her son "cried in pain" from mouth ulcers after undergoing the treatment but was given no proper physical examination.

\section{Side effects of the drugs}

Dr Andrew Herxheimer, senior lecturer in clinical pharmacology and therapeutics at Charing Cross and Westminster Hospitals, told the committee that the drugs prescribed by Dr Gee could cause hazardous side effects. Thyroid extract was an "unpredictable drug" that needed supervision. It speeded up the metabolism, could exacerbate certain forms of angina, and could cause muscular weakness and diarrhoea. Previous medical examination was essential. The drug increased heart rate, could lead to sleeplessness if given to patients with hyperthyroidism, caused blurring of vision, and made the passing of urine more difficult.

Professor Michael Besser, professor of endocrinology and honorary consultant physician at St Bartholomew's Hospital, said the combination of pills used by Dr Gee could be hazardous, and the use of thyroid extract was against normal practice in any reputable British or American medical centre.

Andrew Collins QC, counsel for Dr Gee, submitted at half time that there was no case to answer on the basis that insufficient evidence existed to justify a finding of serious professionel misconduct, but the committee ruled that $\mathrm{Dr}$ Gee should answer the charges.

Giving evidence, Dr Gee insisted there could be no serious side effects from the drugs because the amounts he prescribed were well below those considered to be normal by the medical profession. He said treatment varied from patient to patient, but none received more than $5 \mathrm{mg}$ a day of amphetamine. There was no possibility of dependence.

\section{Conclusions}

A central plank of Dr Gee's case was that he was not a specialist but a general practitioner-Lord Justice Croom-Johnson gave a ruling to this effect in the libel action-and as he was treating patients as their general practitioner he did not have to consult patients' general practitioners in the NHS. Professor John Anderson, professor of community medicine at Guy's Hospital Medical School, said that Dr Gee was offering primary care and had no obligation to notify patients' NHS general practitioners in the circumstances of these cases when patients were not currently receiving active treatment by other general practitioners.

Thirteen satisfied patients-both patients with obesity and others-testified to Dr Gee's ability and concern as a general practitioner. Patients said that he examined them thoroughly and that they had no complaints about their treatment. "He took five stone off of me," said one. Mr Oliver Haywood of Gillingham, Kent, a retired dental surgeon, said Dr Gee helped save his life in diagnosing a heart condition and referring him to a specialist. In addition, around 15 expert witnesses, mainly endocrinologists and biochemists, from Britain and America gave written evidence on $\mathrm{Dr}$ Gee's behalf. 